\title{
Communication and Conflict Resolution
}

\author{
Kristina
}

\begin{abstract}
A conflict is a normal situation to happen as it is the human nature of the which is so varied and dynamic that persons with same perception about one thing may end up in a conflict over the other and Participants in conflicts growing niche to respond on the basis of Reviews their perceptions of the situation. Power is the currency of conflict. Communication is important in any activities. In cooperation even conflict are communication needs. However, Communication can be the source of problems if the information not stated and understanding well. In fact, communication is an alternative way for conflict resolution. This paper will explain the main two roomates later discussion will describe position and role of dialogue paved into peace with Papuas as the study case. First part of this paper will prioritized the discussion about understanding the comprehensive dialogue. In the second part will this discussion focused on the relations between dialogue and Conflict Resolutions.
\end{abstract}

Keywords: communication, conflict resolutions

People have many different images about what power is, some of which are quite misleading. Power is variously defined as the ability to act, to influence an outcome, to get something to happen, or to overcome resistance. For the purpose of understanding the dynamics of conflict, power may be defined as the ability to get one's needs met and to further one's goals. Any form of communication (dialogue, debate, and conversation), opened the establishment of the search process, the expression of thoughts and feelings between two people who do know more. Whatever the context of human relations: cooperation, competition even in an atmosphere of conflict in definite need of communication. Communication contains the value that was so thick that a set procedure in which a sense of feeling that will other affect. This indicates that the communication does not occur orally, in writing, through the mass media, but also through music, 
theater, and in all human behavior. Thought above confirms that communication is a process that involves the transmission of feeling the sender (Communicator) to the receiver (communicant), which has the goal of getting a reaction (feedback).

Humans are imperfect beings (weakest) to communicate. Some conditions such as mistaken, false arrests, misunderstand is clear evidence that shows how a communication error would occur in the human social contact and not on other creatures. Very often these imperfections can cause conflict, and at the time of issue of this communication diiikuti by differences in interests and needs, then the conflict will be more difficult to resolve.

Communications and every problem has already pretty much inspired literature conflict. resolution studies What is emphasized here is how difficult a person to communicate the right things so complex, especially in an emotional state and in a difficult situation. Therefore it is no exaggeration if it is suspected that the weakness of communication, emotions, and feelings of depression will lead to all-round communication situation salah.

Conflicts occur because people generally feel that he has to communicate the right things well when it is not. Communication becomes increasingly laden with problems when followed by a number of factors that also inhibit communication terjalinya well as gender, culture, age, status, and the environment. Knowingly or not humans often communicate with the basic perception of incomplete information and personal experience, which ultimately will only give birth to stereotypes and make a decision from a previous interaction experiences. Even more unfortunately often we take the decision to solve the problem (conflict) without understanding mendalam.

This paper will examine two topics that will describe the position and role of communication in paving the way for peace with a case study in Papua. The early part of this article search discussion prioritize a comprehensive understanding of the dialogue. Then in the second part of the discussion will be focused on the communication link with the Interactive with conflict resolution.

\section{Dialogue: What Do We Understand?}

Communication can be seen as a means of how we deal with and resolve conflicts constructively, and therefore a common response to the conflict, which has escalated towards 
violence is a demand from many quarters for immediate dialogue, which is generally understood as the exchange and discussion of the ideas were idea, presented honestly and openly as an institution towards harmony and interrelatedness relationship pemahaman. This indicates that the misunderstanding is the main source of conflict, escalation or two ways. Then how improved communications is a major step how the escalation of the conflict can be stopped and settled. In this discussion, a very simple question, namely what is the dialogue? A word often used and given a different meaning by the people and in different conditions. In the political arena, for example, we read the news "Obama Calls for 'Strong Dialogue" .

Then the choreographer of La Danse: The Paris Opera Ballet, confirms that the staging they do will create communication through body language. Etymologically, we can get a clue as to what is meant by dialogue. Its ultimate origin is the Greek word "dialogos" , "she" meaning through (through) and "logos" meaning "the meaning of the words" (word) thus the origin of the word communication means through the meaning of the word. Thus the meaning of the communication is flowing to us. As what has been summarized by William Isaacs (1999), there are four capacity to be developed as the foundation behave in a dialogue. First, the delivery (voicing): with regard to speaking the truth in accordance with the authority of someone.

Questions to be answered here is: what should be disclosed? Listening (listening) in the sense here all should listen without objection to what the other party or mengiterupsi; This reflects the answers to questions what is perceived? Yours (respecting) is concerned with the awareness and recognition of the integrity of the position of other people who are very difficult to be understood as a whole; The question here is how this all fits with my views? Suspending refers to "placing or holding" our assumptions, decisions and kenentuan. This involves the question: How all this happened?

Paradigmatically, communication emphasis on the collaboration of a process or activity is new communicates. In a communication of communication is positioned as a complementary mechanism of all participants who collaborate to achieve a goal of communication. Furthermore what is the essence of communication is "social situation" obtained from an environment where the interaction took place and the resulting meaning can only be understood if he was associated with the environmental context in which he dilahirkan. Jay Rothman leave a depiction that there are at least four the type of communication that exist and often practiced in paving the way for peace in conflict areas. The first is the position (Positional) dialog: the parties to the conflict to 
articulate their views and opinions. They met together with the facilitator to talk, but the conversation took place in a state that face to face (I am right and you are wrong) just reflects the conflict.

In this dialog lists the conflicting parties involved in the bargaining power of them and blaming each other for the conflict with each other. In the literature of conflict studies, is often referred to as phase focused on the formulation of views and opinions that differ from the diverse parties (if possible), protects the interrelatedness of understanding of all the differences, and will be used as the substance identification of conflict.

The second is the so-called Human Relations Dialogue: here the conflicting parties facilitated to explore their thoughts about the conflict and their relationship with each other. They herein should remove all forms of stereotyping, began to explore that other people are part of it even puts others as friends. They began to build a sense of trust and understanding of the people involved in the process, although they still have disagreements about the key issues in the conflict. Be the main focus here is the cause of the misunderstanding and stereotype attitudes are always increasing inter-party conflict. The goal here is the mutual understanding, increasing mutual respect between the parties. Thus, what the needs (needs), fear of parties, values, expectations and experiences during the conflict becomes open and understandable.

The third type of communication activists (activist dialogue): here there was a movement forward. The subject of the issue has been selected and analyzed for common ground will be used as the basis for further used as the basis of how the conflict parties want to change their opposition into action together. The point here is to build or provide a foundation for action to be taken by the parties in conflict here gathered together to build up a condition which is symbolized as a city (place) that was completely destroyed as a result of a conflict. Both warring parties here have to do noble things where they need to give aid to the wounded and sick as victims of conflict. In a communication situation like this what you want built is a consciousness in which the destruction is much easier to do than the reconstruction and reconciliation of conflict. With a simple sentence, the main purpose of communication here is not just talks and understanding, but it has reached the level of mutual cooperation and how to provide assistance.

The fourth type of communication is what the study called problem-solving conflict resolution dialogue. In practice, this is often named as a problem solving workshop. The conflicting parties organize their communications so that they could lead to the substance of what 
exactly makes them conflicting. Here communication must include all parties involved in the conflict to megekplorasi their feelings about the conflict and their views of the other party (as in human relations dialogue), but there is a major focus here on what the main needs (human needs) of the parties conflict. Human need is usually the main source of the ongoing conflict. Here the intensive efforts made to provide a framework of conflict for equal attention to the needs of each major, followed by completion of the joint (joint problem solving) to further improve the way toward fulfilling the needs of all parties, which will eventually become the settlement formula konflik.

Four capacity and type of communication above clearly indicate that communication has differences with some of the terminology (synonyms) such discussions, debates, and conversations, often paired but not a dialogue. In the discussion, attention is usually just to listen to and follow the desire to react, waiting for the moment and present ideas in the debate penance berganti. Meantime, what happens is not listening to what the main points but how to give refutation and rebuttal and be a winner. While the discussion is where two or more parties express different thoughts and keep it as a means to conduct a useful analysis of the overall situation and ultimately lead to a conclusion.

Although there is little resemblance especially the discussion, communication is not the same with all four synonyms that have been briefly outlined above. Communication usually display different views as a means to find a new perspective, usually preceded by a complex exploration of the issues. Thus a simple communication emphasizes the difference is not only focused on the approval but give a very spacious room on exploration on various isu.

\section{Communication in the Conflict Resolution}

The success of a communication must include the establishment of re-harmonization of relations that enable the warring parties to arrive at an understanding of the best on the conflict in which they terlibat. Furthermore, Galtung noted that the settlement of a conflict will depend on how, or the extent to which communication mechanism made capable of penetrating the primary source of conflict. Furthermore Galtung also noted the other hand the importance of communication is to create an atmosphere where the parties to the conflict can meet lainya. Between each other view is also interesting to note that through dialogu be good communication (constructive), thus leading at a meeting of the feeling, when feeling has been met then they do not just exchange 
facts, but also to transform, build on the progress and the common good.

Communication is not just an important component of the negotiations, as the path to conflict resolution to bring awareness to our communication with all parties involved in the conflict how to be a good listener. Human communication error because they merely loud speaker but have never become a good listener, loyal, and empathy. Hearing will improve the understanding of the diverse cultures, values, and norms that would be a major foothold towards completion konflik.18 With the assumption can be said that communication is used not only to improve the existing mechanism but it could be to create new mechanisms as illustrated by Norbert Ropers with communication we will get:

...improvement of relations, opening up the possibility of head interrelatedness understanding, define and realize what the role of the parties involved in the conflict, and the opportunity to open up new ideas for the future of the settlement conflict.

Success or failure of the implementation of the dialogue, if you follow Chris Mitchel thoughts can be evaluated in three levels.

1. Its impact on the people involved (the change in attitude, a new pattern of behavior)

2. output, In terms of ideas, suggestions, practical assessment that will be included in the process of formation of interest.

3. Long term impact on the overall conflict.

In all three levels of success or failure of a communication can be seen by comparing the situation before and after the execution of the dialogue. To level participants what could be a reference tto a success is if there is a change of perception about the conflicts experienced, the extent to which mutual understanding is getting an increase and followed a process where there is an agreement to act in the future.

As one means of intervention in conflict resolution, communication typically includes exposure history and practice of active listening is claimed that if successful will bring the conflict that had been destructive could be transformed into constructive conflict with some of the following characteristics:

1. There is clarity, definition, of the problems faced.

2. No longer cover what interests and needs. 


\section{Find and prioritize options}

4. The implementation of a peaceful ways (new communication)

5. Increase interrelatedness pemahaman.

As a model in conflict penetrate, to use the term Ronald J. Fisher, communications often get a place in the mechanism of "Interactive Conflict Resolution". Experts conflict eminent putting methods of communication in conflict resolution mechanism is John Burton, founder of the center of conflict analysis at the University College, London, who organized the "control communication" workshop that focuses on the conflict between Indonesia and Malaysia and Cyprus, in the mid-60s , Herbert Kelman of Harvard University who developed an approach to interaction (interactional approach) of "problem solving workshop" together with Stephen Cohen, Edward Azar, focusing on the conflict in the Middle East. Then Leonard Doob also develop mechanisms for conflict management workshop in African conflicts.

The group of experts with a developed mechanism as mentioned above in the development of conflict resolution studies are often referred to as a (interactive conflict resolution) because it gives weight to the effective and constructive face to face interaction between the representatives of the conflicting parties as well the completion of the internal and international conflicts. In a narrow sense, Kominikasi in conflict resolution is defined as involving a small group, problemsolving discussions among representatives of unofficial groups or the identity of the countries involved in the conflict, facilitated by a neutral party consisting of academics social. While in the broad sense as well as guidance in this paper RKI is how to facilitate the activities of face-to-face dialogue, training, education, and consultation that promote conflict analysis, collaborative problem solving between the parties involved in the conflict, which will be able to meet human needs and promote peace building justice and equality.

The main assumptions in conflict resolution communication is a constructive analysis and creative problem solving between the parties adequate. Communication as a method here must include psycho-social approach to ensure that issues such as the relationship (a misunderstanding, unfulfilled and disjointed needs) should be touched and the conflict will be resolved only with the solution acceptable to all sides and built through interaksi. 


\section{Conclusion}

Of the many publications that already exist on the association of communication as a means of intervention in managing the conflict there are at least nine subjects that will be very beneficial to the process mengelolaan a conflict.

To arrive at an ambitious settlement (resolution) of a conflict, this will only be achieved through a process that will require not only a relatively long time, but also must be accompanied by patience and good faith of all parties to come to the commitment towards on future improvements. This is evident not making this up as a personal confidence building, clarity of positioning, and perceptions about the fact that experienced conflict is a requirement that must be included in a dialog. The process of communication is beginning to get something better. Communication to the dispute would be very nice to be implemented through the assistance of third parties who have the knowledge and ability provide open space for all the representatives of the conflicting parties to become a hero of the future for the sake of dating. A resolution mechanism that is born of the communication process will always include your name and where communication is carried out.

The biggest challenge in the process of a communication is to ensure mastery of facilitation methods and techniques to communicate. The first thing associated with the preparation, financial aid, and the place where the communication will be implemented. Determining where communication will be implemented are the strengths and weaknesses of the communication at the same time, as a neutral space will be a force and if the place were not impartially then communication is open space to reap failure.

\section{References}

Adejimola, Amuseghan Sunday, Language and communication in conflict resolution Department of Arts Education, Adekunle Ajasin University, Akungba-Akoko, Journal of Law and Conflict Resolution Vol. 1 (1), pp. 001-009, June, 2009

Apple. Diskurs 1990. Karl-Otto und Verantwortung, Suhrkamp Frankfurt. In Norbert Ropers. 2003. From Resolution to Transformation: The Role of Dialogue Projects. Berghof Research Center for Constructive Conflict Management.

Brenner. L. Nurette beyond 2011. The Field Doing Wrong and Doing it Right: A study of Arab- 
Jewis Grassroot Dialogue Group in the United States. Dissertation, Department of Organizational Behavior. Case Western Reserve University.

Bohm, David, 2004. On Dialogue, edited by Lee Nichol, New York, Routledge Classic.

Brett, M. Jeanne. 2007. Social dilemmas, Negotiating Globally: How to Negotiate, Deals, Resolve Disputes, and Make Decisions across Cultural Boundaries. Springer Verlag.

Clark. H. Herbert. 1996. Using Language. Cambridge. Cambridge University Press.

Cohen, Raymond. 1991. Negotiating Across Culture; Communication Obstacles in International Diplomacy. Washington DC. USIP. Press.

C. Shannon, Weaver W. (1977). The Mathematical Theory of Communication in: W. Schram and DF Roberts. The Process and Effects of Mass Communication., Illinois: University of Illinois Press.

Fisher, Ronald J. 1997. Interactive Conflict Resolution. Syracuse University Press.

Fisher, Rojer and William Ury, 1981. Getting to Yess: Negotiating Agreement Without Giving Galtung. Johan. 2004. Saturday: Transcend and Transformed: An Introduction to Conflict Works. England, Pluto Press.

Edward T. Hall. 1959. The Salient Language.

Garden City. New York. Doubleday.

Isaacs, William, 1999. Dialogue and the Art of Thinking Together, New York Doubleday, Random House.

Kahn. Michael 1981. The Seminar: An Experiment on Humanistic Education. Journal of Humanistic Psychology. No. 21. 119-127.

Kolb, Deborah. 1994. The Reality of Making Work Talk, Talk When Work: Profiles of mediators. Jossey Brass.

Mayer. Bernard, 2000. The Dynamics Of Conflict Resolution: A Practitioner 's Guide, San Francisco, Josey-Bass, A Wiley Company.

Michell, Christopher and Michael Banks, 1996. Handbook of Conflict Resolution: The Analytical Problem Solving Apparoach. Pinter, Wellington House. London.

Nopers, Robert, 2003. From Resolution to Transformation: The Role of Dialogue Projects. Berghof Research Center for Constructive Conflict Management.

Putnam. Linda L. Communication and Conflict Resolution, Department of Communication University of California, Santa Barbra. 
Jay Rothman 1998. "Dialogue in Conflict: Past and Future". In Eugene Weiner, 1998 (editor). The Handbook of Interethnic Coexistence, New York Continuum.

AO Scott, La Danse: The Paris Opera Ballet. The New York Times, Nove 6, 2009.

Alan C. Tidwell, 1998. Conflict Resolved ?: A Critical Assessment of Conflict Resolution, London, New York: Pinter Books.

Edward Wong and Helenne Cooper, In Beijing, Obama Calls for 'Strong Dialogue ". The New York Times, Nove 16, 2009. 
